Check for updates

Cite this: Chem. Sci., 2019, 10, 9339

๑ All publication charges for this article have been paid for by the Royal Society of Chemistry

Received 26th June 2019

Accepted 20th August 2019

DOI: $10.1039 / \mathrm{c} 9 \mathrm{sc} 03144 \mathrm{~h}$

rsc.li/chemical-science

\section{The importance of intramolecular conductivity in three dimensional molecular solids $\uparrow$}

\author{
Melissa L. Ball, (D) a Boyuan Zhang, ${ }^{a}$ Tianren Fu, ${ }^{\text {ab }}$ Ayden M. Schattman, ${ }^{a}$ \\ Daniel W. Paley, ${ }^{a}$ Fay Ng, ${ }^{a}$ Latha Venkataraman, (D) *ab Colin Nuckolls (D) *a \\ and Michael L. Steigerwald ${ }^{\star a}$
}

\begin{abstract}
Recent years have seen tremendous progress towards understanding the relation between the molecular structure and function of organic field effect transistors. The metrics for organic field effect transistors, which are characterized by mobility and the on/off ratio, are known to be enhanced when the intermolecular interaction is strong and the intramolecular reorganization energy is low. While these requirements are adequate when describing organic field effect transistors with simple and planar aromatic molecular components, they are insufficient for complex building blocks, which have the potential to localize a carrier on the molecule. Here, we show that intramolecular conductivity can play a role in controlling device characteristics of organic field effect transistors made with macrocycle building blocks. We use two isomeric macrocyclic semiconductors that consist of perylene diimides linked with bithiophenes and find that the trans-linked macrocycle has a higher mobility than the cisbased device. Through a combination of single molecule junction conductance measurements of the components of the macrocycles, control experiments with acyclic counterparts to the macrocycles, and analyses of each of the materials using spectroscopy, electrochemistry, and density functional theory, we attribute the difference in electron mobility of the OFETs created with the two isomers to the difference in intramolecular conductivity of the two macrocycles.
\end{abstract}

\section{Introduction}

Understanding how molecular structure impacts mobility in organic field effect transistors (OFETs) has garnered much attention in recent years. ${ }^{1-6}$ Small, flat aromatic molecules, such as linear acenes, have been widely used as the active layer in organic semiconductors due to their relatively high carrier mobilities in both films and single crystal devices. The high carrier mobilities are attributed to strong intermolecular interaction amongst adjacent molecules and low intramolecular reorganization energy. ${ }^{7-9}$ While these two requirements govern charge transport for small, flat aromatic molecules, they are insufficient for complex, three dimensional molecules. In the latter, carriers can become localized, impeding transport. Examples of three dimensional molecular prototype are fullerenes and fullerene derivatives, ${ }^{\mathbf{1 0}}$ which are ntype materials used in OFETs, ${ }^{\mathbf{1 1}-13}$ organic photovoltaics

${ }^{a}$ Department of Chemistry, Columbia University, New York, New York 10027, USA. E-mail:lv2117@columbia.edu; cn37@columbia.edu; mls2064@columbia.edu

${ }^{b}$ Department of Applied Physics and Applied Math, Columbia University, New York, New York 10027, USA

$\dagger$ Electronic supplementary information (ESI) available: Experimental procedures for the synthesis and characterization, UV-vis spectroscopy, cyclic voltammetry, STM-BJ setup and data, crystallographic data (CIF), OFET characterization, and computational details. See DOI: 10.1039/c9sc03144h
(OPVs) ${ }^{\mathbf{1 4 - 1 6}}$ and organic photodetectors (OPDs). ${ }^{\mathbf{1 6 , 1 7}}$ However, fullerenes are difficult to synthesize and functionalize, and their optical properties cannot be easily tuned. This prompts the search for alternatives that both absorb visible light and retain structural features, such as a three-dimensional shape. ${ }^{18-22}$

Here, we study a sub-class of three dimensional, organic materials called conjugated macrocycles. Conjugated macrocycles possess several structural and electronic advantages over acyclic molecules: (1) their contorted structure can facilitate intermolecular contact and charge transport; ${ }^{19,23}$ (2) they contain no end groups that can act as trap sites in linear molecules; ${ }^{24-27}$ (3) they often absorb more visible light than linear molecules; ${ }^{28,29}$ and (4) their intramolecular cavities can act as a host for electronic guests. ${ }^{30-35}$ We create OFETs with three dimensional molecular solids made from macrocyclic organic semiconductors illustrated in Fig. 1, and describe the role of intramolecular conductivity on their performance. We find that intramolecular conductivity has an appreciable effect on the semiconductors' transport properties. While electronically active macrocycles have been used in organic devices such as transistors, photovoltaics and detectors in recent years, ${ }^{23,29,33,36-41}$ the impact of molecular structure on device performance is an ongoing field of research. ${ }^{41}$ Our macrocycles were designed to enhance intermolecular interactions through 
(a) PDI

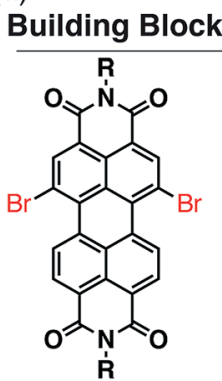

1,6-dibromo PDI

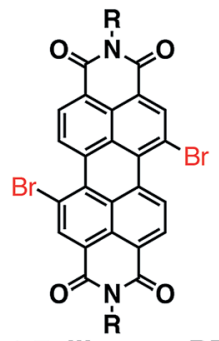

1,7-dibromo PDI (b) 3D

Semiconductors
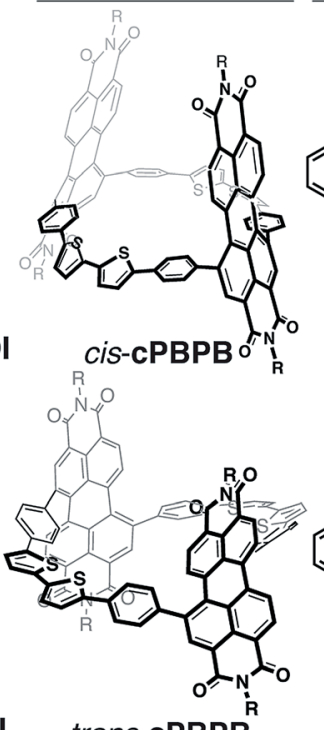

trans-cРBPB (c) Acyclic

Semiconductors
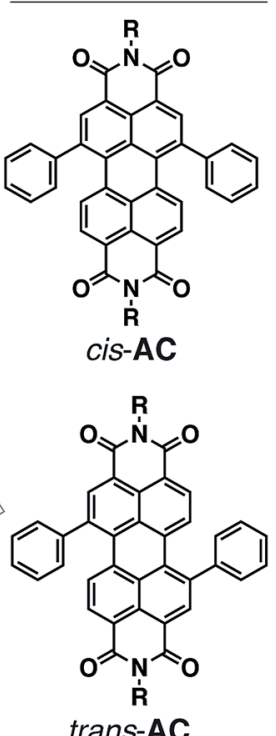

Fig. 1 Structures of (a) 1,6- and 1,7-dibromo PDI, with the cis/trans orientation indicated in red; (b) cis-CPBPB and trans-CPBPB; and (c) structures of acyclic PDI derivatives. cis- and trans-based semiconductors are derived from 1,6-dibromo PDI and 1,7-dibromo PDI, respectively. $\mathrm{R}=$ branched $\mathrm{C}_{11} \mathrm{H}_{23}$ side chains.

$\pi-\pi$ coupling while allowing for synthetic flexibility to control their electronic properties.

\section{Results}

We utilize two types of perylenediimide (PDI) macrocycles that differ in their connectivity to the phenyl-bithiophene-phenyl linker: the PDI and linker are in a trans orientation for transCPBPB and cis orientation for cis-cPBPB (Fig. 1b). trans-cPBPB incorporates a 1,7-substituted PDI isomer into the synthesis while cis-cPBPB comprises a 1,6-substituted PDI isomer (Fig. 1).

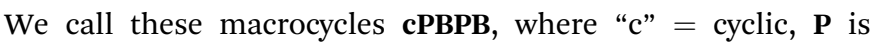
diphenyl PDI, and $\mathbf{B}$ is bithiophene. We previously reported the synthesis of trans-cPBPB.$^{42}$ We measure the device performance in OFETs, and show that electrical mobilities are three times higher in the trans-based devices than in the cis-based devices. We study the materials on a single molecule level with macrocyclic components, use control experiments, computations, and spectroscopy to determine that the difference in electron mobility in OFETs made with the two macrocyclic isomers is due to the difference in intramolecular conductivity. This study demonstrates that intramolecular carrier pathways affect electron transport in three-dimensional molecular solids.

We first investigate the impact from the cis- or trans-linkage on the electrical properties of OFETs made using trans- and cisCPBPB (Fig. 2). Both trans-cPBPB and cis-cPBPB exhibit n-type characteristics and not p-type characteristics. To validate if the materials show any p-type characteristics, we set the source voltage at $-80 \mathrm{~V}$ and swept the gate voltage to $-80 \mathrm{~V}$. From this measurement, we didn't observe any current in the negative

gate region, which confirms the material doesn't show p-type characteristics. The devices show some leakage current due to the large difference between the gate voltage when we sweep from $80 \mathrm{~V}$ to $-20 \mathrm{~V}$ and the source-drain current $(80 \mathrm{~V}) . \$$ The ESI $\dagger$ contains the output curves for the two macrocycles (Fig. S1†).

Fig. 2a and b display the current versus applied gate voltages (transfer curves) for a trans and cis device. We collected the data for these transfer curves using a source-drain voltage of $80 \mathrm{~V}$ while sweeping the gate voltage from $-20 \mathrm{~V}$ to $80 \mathrm{~V}$. The mobility was calculated in the saturation regime ${ }^{3,43}$ using $I_{\mathrm{DS}}=$ $(W / 2 L) C_{\mathrm{i}} \mu\left(V_{\mathrm{G}}-V_{\mathrm{T}}\right)^{2}$, where $W$ and $L$ are the width and length of the channel, $C_{\mathrm{i}}\left(11.5 \mathrm{nF} \mathrm{cm}^{-2}\right), \mu, V_{\mathrm{G}}$, and $V_{\mathrm{T}}$ correspond to the capacitance per unit area of the gate insulator, the field effect mobility, the gate voltage, and the threshold voltage, respectively. We find the mobility in trans-cPBPB is three times that in cis-cPBPB $\left(1.3 \times 10^{-3} \mathrm{~cm}^{2} \mathrm{~V}^{-1} \mathrm{~s}^{-1}\right.$ versus $0.4 \times 10^{-3} \mathrm{~cm}^{2} \mathrm{~V}^{-1}$ $\mathrm{s}^{-1}$ ). We reproduce these mobility measurements across many samples. For example, we made ten devices with each isomer and found that the same values for the mobilities. Table 1 provides the averaged data for each macrocycle.

As morphology is known to have a profound effect on mobility, we first examined the film morphology using atomic force microscopy (AFM) to see if morphological differences could explain the difference in mobility. ${ }^{2,5,44,45}$ Both films were continuous and smooth, and had a room-mean-square roughness of $0.35 \mathrm{~nm}$ and $0.37 \mathrm{~nm}$ for cis-cPBPB and trans-cPBPB, respectively (Fig. 2c and d). The powder/thin-film X-ray diffraction (PXRD) of both films too shows no signs of crystallinity (Fig. S2 $\dagger$ ). Taken together, the lack of difference (and the featurelessness of) in the PXRD and AFM data for the two isomers reveals that the difference in mobility cannot be attributed to morphological or crystallinity differences. Therefore, any differences in packing between the two isomers would need to be on an extremely short length scale.

We then used density functional theory (DFT) calculations to probe the differences in the molecular conformations and structures for trans-cPBPB and cis-cPBPB. Fig. 3 contains the lowest energy structures for cis-cPBPB and trans-cPBPB determined from DFT using 6-31G/B3LYP level of computation. We see that the PDI units remain upright in trans-cPBPB while they bow inward toward the cavity in cis-cPBPB. The PDI-linker connection differs between the two isomers. The torsional angle is greater in the cis molecule relative to trans-cPBPB. This causes the PDI and linker to possess a relatively more orthogonal relationship, and decreases the electronic coupling in cisCPBPB (Fig. 3a and b). The colors of the macrocycles support trans-CPBPB is more conjugated: cis-cPBPB is purple by visual inspection, and trans-cPBPB is black.

We next consider the packing of these macrocycles with the crystal structure of trans-cPBPB (shown in Fig. $3 \mathrm{c}$ and ESI $\dagger$ ). We see that the macrocycles pack with the PDI face of one adjacent to that of another, though with opposite chirality. ${ }^{46-48}$ We were unable to obtain cis-cPBPB's crystal structure, but anticipate a similar face-to-face packing, given the DFT-based structure presented here. The differences in the packing between the two isomers could result in an intermolecular effect on the 
(a)

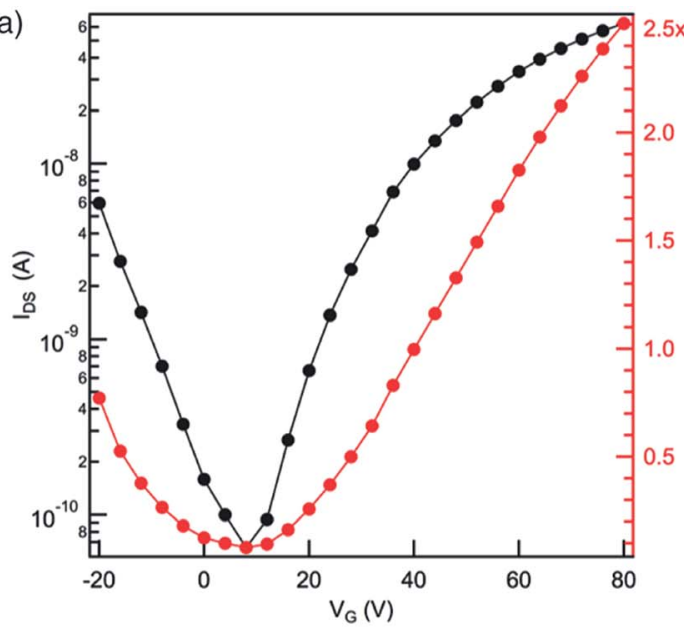

(c)

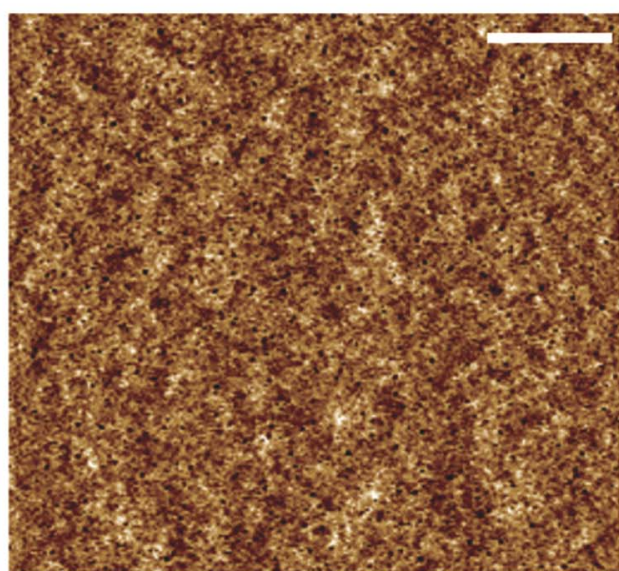

(b)

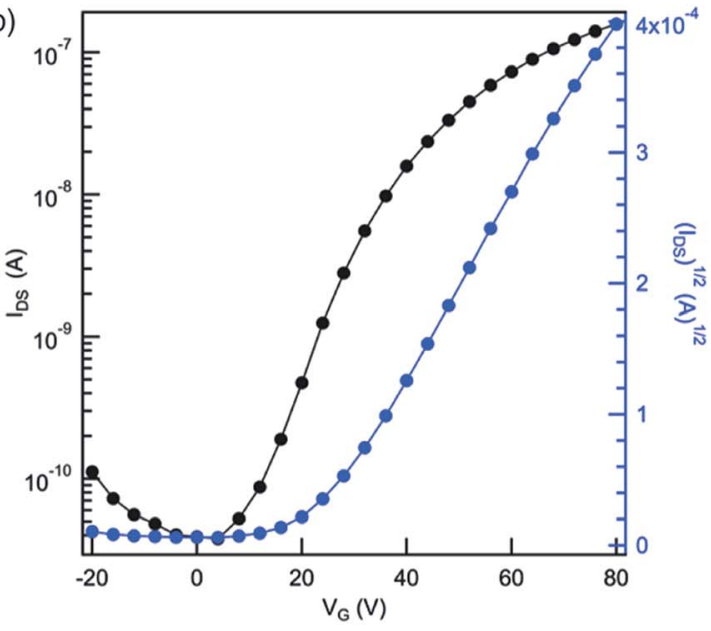

(d)

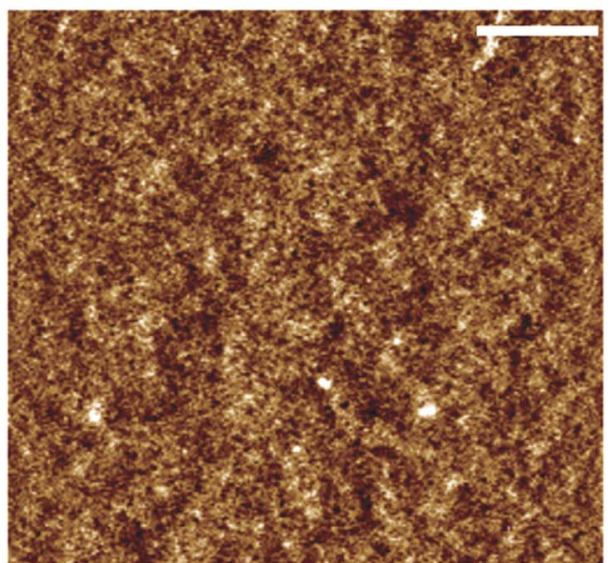

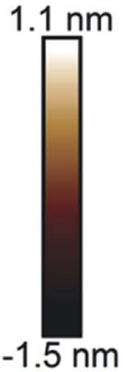

Fig. 2 Electrical characteristics and morphology of the cPBPB OFETs. (a) Transfer curve for cis-cPBPB; (b) transfer curve for trans-cPBPB. Device current (left axis, black) and square root of current (right axis, red or blue) measured as a function of gate voltage at a constant source-drain voltage of $80 \mathrm{~V}$. The trans-cPBPB device has a higher current than the cis-cPBPB at a high and positive gate voltage, indicating a higher mobility for $n$-type carriers. (c) Height image for cis-cPBPB and (d) trans-cPBPB. Both films are continuous and smooth and have a root mean square roughness of 0.35 and $0.37 \mathrm{~nm}$ for the cis and trans-based devices, respectively. The scale bar is $1.0 \mu \mathrm{m}$.

conductivity that could also contribute to the difference in mobility, but we reiterate that the films are amorphous and featureless for each of the isomers.

In addition, its known that molecular strain and rigidity can influence charge transport in macrocyclic semiconductors with the more strained systems having lower intermolecular coupling and hence lower intermolecular conductivity and lower mobility. ${ }^{41}$ We calculate the enthalpy difference between the macrocycle and an acyclic analog (i.e., a homodesmotic calculation ${ }^{28,49-51}$ ) to assess the strain energy in trans-cPBPB and cis-cPBPB. We found only a small $\left(2 \mathrm{kcal} \mathrm{mol}^{-1}\right)$ difference in strain energy and therefore conclude that this does not explain the difference in mobility. The ESI $\uparrow$ contains the details of the calculations used to assess the strain energy.

As these macrocyclic materials are n-type semiconductors, we wondered if a difference in reduction potentials would explain the difference in mobility. We used cyclic voltammetry (CV) to estimate the lowest unoccupied molecular orbital

Table 1 Comparison of trans-cPBPB and cis-cPBPB ${ }^{a}$

\begin{tabular}{llll}
\hline & Mobility $\mu \mathrm{cm}^{2} \mathrm{~V}^{-1} \mathrm{~s}^{-1}$ & LUMO level $^{b}(\mathrm{eV})$ & Optical gap $^{c}(\mathrm{eV})$ \\
\hline trans-cPBPB & $(1.2 \pm 0.1) \times 10^{-3}$ & -3.82 & 1.78 \\
cis-cPBPB & $(0.4 \pm 0.1) \times 10^{-3}$ & -3.79 & 1.85 \\
trans-AC & $(1.5 \pm 0.3) \times 10^{-4}$ & -3.74 & 2.10 \\
cis-AC & $(1.9 \pm 0.3) \times 10^{-4}$ & -3.74 & 2.10
\end{tabular}

${ }^{a} \mathrm{CV}$, optical gap and FET performance for the two macrocycles and acyclic controls. ${ }^{b}$ LUMO levels were estimated from onset of the first reduction peaks. ${ }^{c}$ Optical band gaps were estimated from the onset of absorption. 


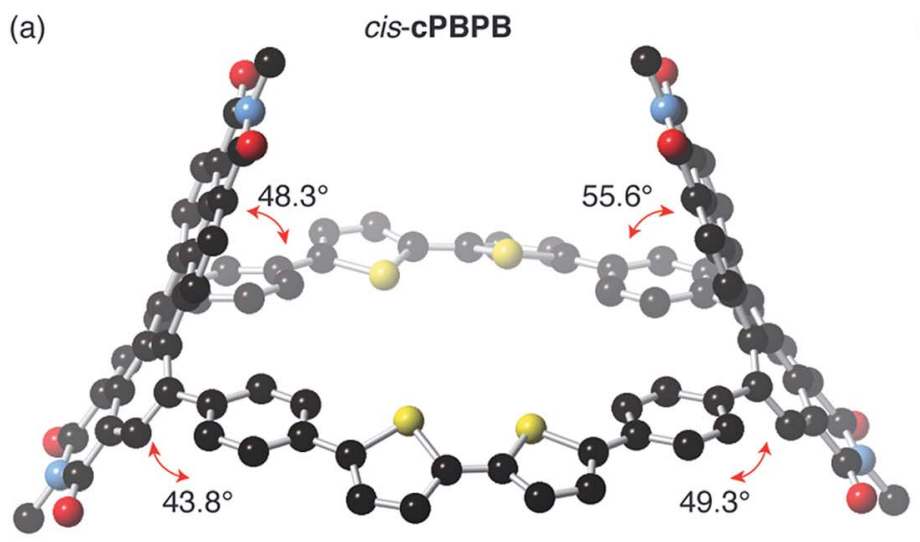

(b)
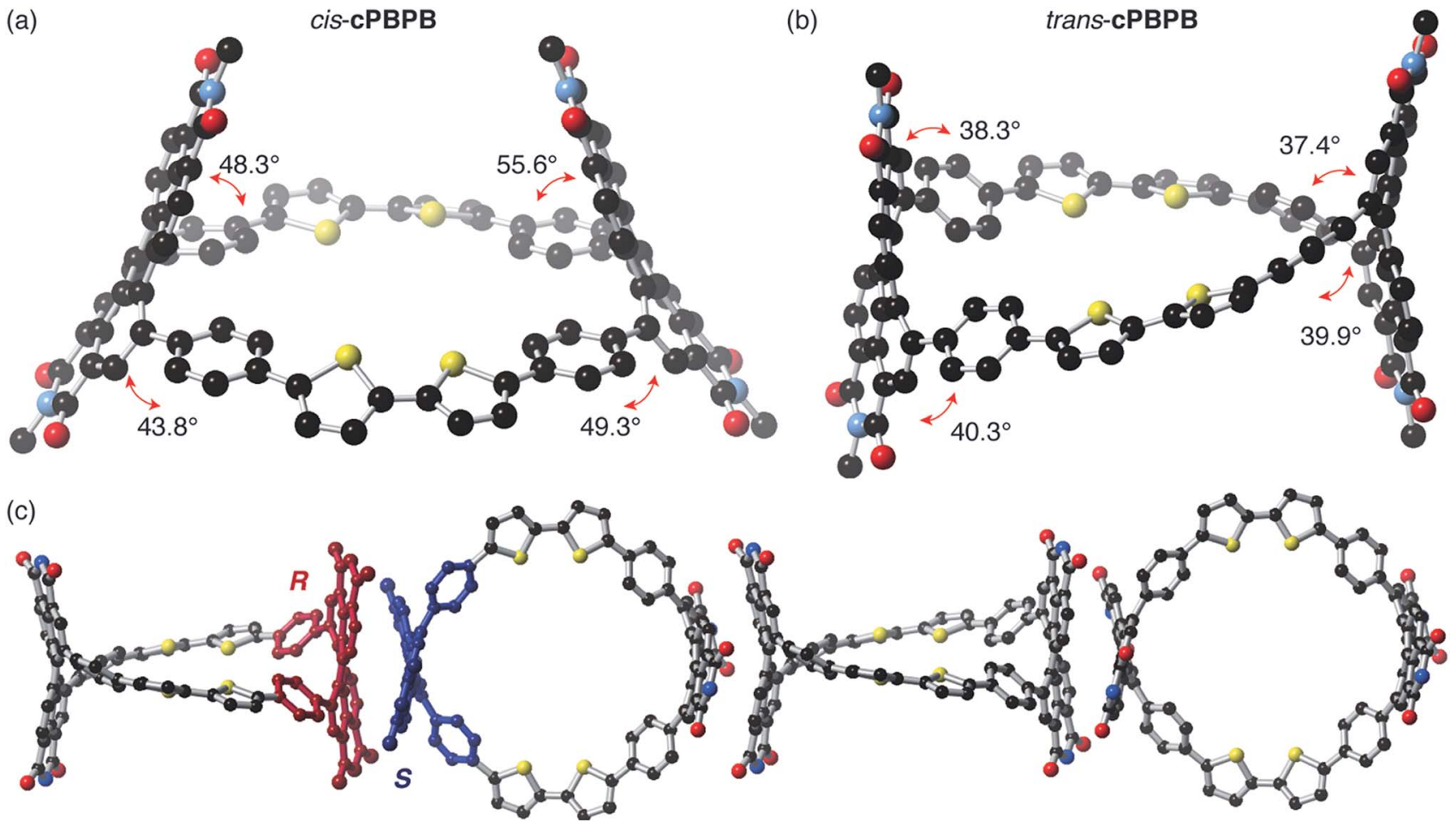

Fig. 3 Molecular structures obtained with DFT using 6.31G/B3LYP basis set. (a) cis-cPBPB and (b) trans-cPBPB. (c) SCXRD solid-state packing of trans-cPBPB as viewed down the $a$ axis. Blue and red are the two enantiomers of the diphenyl PDI packing down the axis. Red $=$ oxygen, blue $=$ nitrogen, black $=$ carbon, and yellow $=$ sulfur. Hydrogens and side chains have been removed for clarity.

(LUMO) energies for both trans- and cis-cPBPB (Table 1, Fig. S3†). trans-cPBPB and cis-cPBPB have similar reduction potentials, as estimated from the onset of the first reduction peak..$^{52}$ We also examined the electronic structure using UV-vis. The UV-vis spectrum suggests trans-cPBPB is more conjugated. The lowest energy transition is at a lower energy in trans-cPBPB than in cis-cPBPB. Moreover, trans-cPBPB has a smaller optical

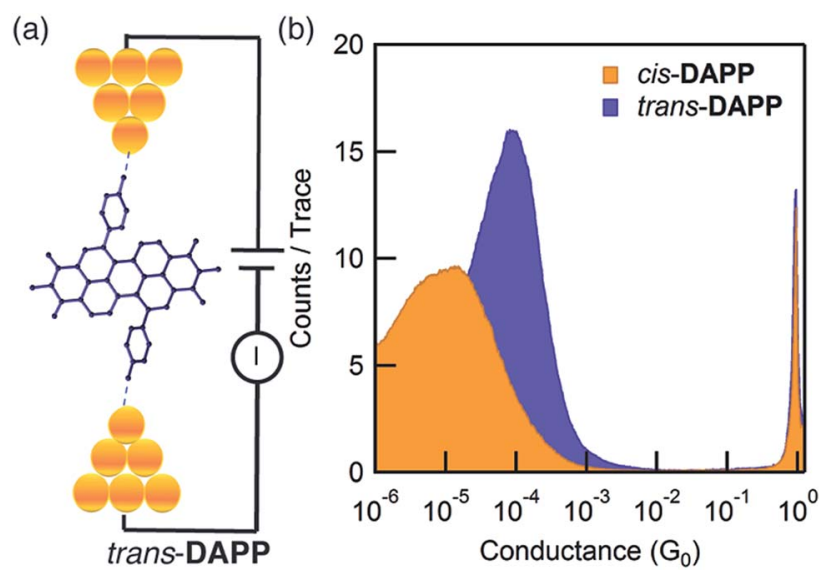

Fig. 4 (a) Schematic of a single-molecule junction showing transDAPP in the break junction. The diphenyl PDI contains two aurophilic amino groups on the aryl rings to bind the gold electrodes in the junction; (b) logarithm conductance histograms for cis-DAPP (yellow) and trans-DAPP (purple) measured with an applied bias of $450 \mathrm{mV}$ in a 1,2,4-trichlorobenzene solution. gap than the cis-cPBPB macrocycle (Table 1, Fig. S4†). This likely reflects greater orbital overlap, given the smaller torsional angle between the linker and the PDI (Fig. 3a and b).

We next evaluate the intramolecular conductivity by deconstructing the macrocycles into 1,6- and 1,7-diphenyl PDI monomers that possess two aurophilic amino groups on the aryl rings. We refer to these molecules as trans-DAPP and cisDAPP (Fig. 4a and ESI III $\dagger$ ). While the cis and trans PDI isomers are well known, ${ }^{53-56}$ the difference in intramolecular conduction between the cis and trans isomers has not been reported until now. The two aurophilic amino groups on the aryl rings bind the $\mathrm{Au}$ electrodes in the STM-BJ setup ${ }^{57-60}$ to form Au-DAPP-Au junctions (Fig. 4a). We found that trans-DAPP has a conductance nearly one order of magnitude higher than cis-DAPP at $\sim 8.6 \times 10^{-5} G_{0}$ compared with $\sim 1.0 \times 10^{-5} G_{0}$ (Fig. 4 b), where $G_{0}=e^{2} / h$ is the conductance quantum. Fig. S5 $\dagger$ contains the two-dimensional histograms for cis- and trans-DAPP and details for the experimental setup.

Because the STM-BJ studies determined that transsubstituted PDI molecular junctions are better conductors than cis-substituted PDI junctions, we hypothesized that the difference in the mobilities seen for trans- and cis-cPBPB based OFETs is due to the trans/cis substitution patterns. The experiments described next find that the substitution patterns in the acyclic subunits do not explain the differences in mobility between the two three-dimensional macrocyclic semiconductors, cis-cPBPB and trans-cPBPB. 
We synthesized the acyclic relatives of trans- and cis-cPBPB, cis- and trans-AC, which comprise a diphenyl PDI substituted in a cis and trans orientation (Fig. 1c). We made OFETs using cisand trans-AC, and find that the two have similar averaged electron mobilities: $1.9 \times 10^{-4} \mathrm{~cm}^{2} \mathrm{~V}^{-1} \mathrm{~s}^{-1}$ and $1.5 \times 10^{-4} \mathrm{~cm}^{2}$ $\mathrm{V}^{-1} \mathrm{~s}^{-1}$ for cis-AC and trans-AC, respectively (see Table 1, ESI Table S1 and Fig. S6† for details). We also studied the film morphology using AFM, and both films were smooth, with a root mean square roughness of 0.43 and $0.45 \mathrm{~nm}$ for $\mathrm{cis}$ - and trans-AC, respectively (Fig. S7†). Since cis-AC and trans-AC show similar mobilities in OFETs, the cis and trans substitution pattern alone is not the reason for the difference in the performance found in the macrocyclic systems.

\section{Conclusions}

Both trans-cPBPB and trans-AC possess a trans linkage, suggesting higher intramolecular conductivity than the cis analogues from the STM-BJ measurements. Yet OFET devices from either trans- or cis-AC show similar electron mobilities, while electron mobilities from trans-cPBPB or cis-cPBPB macrocycles show marked differences in their mobilities. From this data, we conclude that the substitution pattern in the subunits is not responsible for the difference in charge transport in the acyclic controls, but influences charge transport for the relatively complex three dimensional semiconducting macrocycles. transCPBPB is more conjugated than cis-cPBPB, as reflected in the UV-vis data, suggesting that the intramolecular conductivity is higher in the trans-based macrocycle. Together, the acyclic control data, STM-BJ measurements, and spectroscopy demonstrate that intramolecular carrier pathways affect charge transport as the complexity of the molecule increases in molecular solids. For both isomers, the films are featureless, flat, and amorphous, implying that the morphology of the films and the crystal packing is not responsible for the difference in mobility. This study reveals the importance of not just intermolecular interactions and reorganization energy as conditions for electrical conduction in OFETs but also shows the importance of intramolecular conduction.

\section{Funding sources}

Primary support for this project was provided by the Chemical Sciences, Geosciences and Biosciences Division, Office of Basic Energy Sciences, U.S. Department of Energy (DOE), under award no. DE-SC0019440. The Columbia University Shared Materials Characterization Laboratory (SMCL) was used extensively for this research. We are grateful to Columbia University for support of this facility. TF acknowledges financial support from the National Science Foundation under award grant CHE1764256. No competing financial interests have been declared.

\section{Conflicts of interest}

There are no conflicts to declare.

\section{Acknowledgements}

We thank the Guthikonda family for their financial support of MLB through the Arun Guthikonda Memorial Graduate Fellowship. C. N. thanks Sheldon and Dorothea Buckler for their generous support. Single crystal X-ray diffraction was performed at the Shared Materials Characterization Laboratory at Columbia University. Use of the SMCL was made possible by funding from Columbia University.

\section{Notes and references}

$\ddagger$ The current seen from the negative voltage is related to leakage current and does not represent an ambipolar device.

1 J. L. Brédas, J. P. Calbert, D. A. da Silva Filho and J. Cornil, Proc. Natl. Acad. Sci. U. S. A., 2002, 99, 5804-5809.

2 M. Bendikov, F. Wudl and D. F. Perepichka, Chem. Rev., 2004, 104, 4891-4946.

3 C. R. Newman, C. D. Frisbie, D. S. Filho, J.-L. Brédas, P. C. Ewbank and K. R. Mann, Chem. Mater., 2004, 16, 4436-4451.

4 J. E. Anthony, Chem. Rev., 2006, 106, 5028-5048.

5 A. R. Murphy and J. M. J. Fréchet, Chem. Rev., 2007, 107, 1066-1096.

6 A. Onwubiko, W. Yue, C. Jellett, M. Xiao, H.-Y. Chen, M. K. Ravva, D. A. Hanifi, A.-C. Knall, B. Purushothaman, M. Nikolka, J.-C. Flores, A. Salleo, J.-L. Bredas, H. Sirringhaus, P. Hayoz and I. McCulloch, Nat. Commun., 2018, 9, 416.

7 Y. Lin, D. J. Gundlach, S. F. Nelson and T. N. Jackson, IEEE Electron Device Lett., 1997, 18, 606-608.

8 D. J. Gundlach, J. A. Nichols, L. Zhou and T. N. Jackson, Appl. Phys. Lett., 2002, 80, 2925-2927.

9 V. Coropceanu, J. Cornil, D. A. da Silva Filho, Y. Olivier, R. Silbey and J.-L. Brédas, Chem. Rev., 2007, 107, 926-952.

10 H. W. Kroto, J. R. Heath, S. C. O'Brien, R. F. Curl and R. E. Smalley, Nature, 1985, 318, 162-163.

11 R. C. Haddon, A. S. Perel, R. C. Morris, T. T. M. Palstra, A. F. Hebard and R. M. Fleming, Appl. Phys. Lett., 1995, 67, 121-123.

12 H. Li, B. C.-K. Tee, J. J. Cha, Y. Cui, J. W. Chung, S. Y. Lee and Z. Bao, J. Am. Chem. Soc., 2012, 134, 2760-2765.

13 Y. Zhang, I. Murtaza and H. Meng, J. Mater. Chem. C, 2018, 6, 3514-3537.

14 L. Dou, J. You, Z. Hong, Z. Xu, G. Li, R. A. Street and Y. Yang, Adv. Mater., 2013, 25, 6642-6671.

15 B. M. Savoie, N. E. Jackson, L. X. Chen, T. J. Marks and M. A. Ratner, Acc. Chem. Res., 2014, 47, 3385-3394.

16 B. M. Savoie, A. Rao, A. A. Bakulin, S. Gelinas, B. Movaghar, R. H. Friend, T. J. Marks and M. A. Ratner, J. Am. Chem. Soc., 2014, 136, 2876-2884.

17 X. Gong, M. Tong, Y. Xia, W. Cai, J. S. Moon, Y. Cao, G. Yu, C.-L. Shieh, B. Nilsson and A. J. Heeger, Science, 2009, 325, 1665-1667.

18 C. B. Nielsen, S. Holliday, H.-Y. Chen, S. J. Cryer and I. McCulloch, Acc. Chem. Res., 2015, 48, 2803-2812. 
19 M. Ball, Y. Zhong, Y. Wu, C. Schenck, F. Ng, M. Steigerwald, S. X. Xiao and C. Nuckolls, Acc. Chem. Res., 2015, 48, 267276.

20 C. Yan, S. Barlow, Z. Wang, H. Yan, A. K.-Y. Jen, S. R. Marder and X. Zhan, Nat. Rev. Mater., 2018, 3, 18003.

21 J. Zhang, H. S. Tan, X. Guo, A. Facchetti and H. Yan, Nat. Energy, 2018, 3, 720-731.

22 J. Hou, O. Inganäs, R. H. Friend and F. Gao, Nat. Mater., 2018, 17, 119.

23 M. Ball, B. Zhang, Y. Zhong, B. Fowler, S. Xiao, F. Ng, M. Steigerwald and C. Nuckolls, Acc. Chem. Res., 2019, 54, 1068-1078.

24 M. M. Mandoc, B. de Boer, G. Paasch and P. W. M. Blom, Phys. Rev. B: Condens. Matter Mater. Phys., 2007, 75, 193202.

25 L. G. Kaake, P. F. Barbara and X.-Y. Zhu, J. Phys. Chem. Lett., 2010, 1, 628-635.

26 A. C. Arias, J. D. MacKenzie, I. McCulloch, J. Rivnay and A. Salleo, Chem. Rev., 2010, 110, 3-24.

27 H. T. Nicolai, M. Kuik, G. A. H. Wetzelaer, B. de Boer, C. Campbell, C. Risko, J. L. Brédas and P. W. M. Blom, Nat. Mater., 2012, 11, 882-887.

28 T. Iwamoto, Y. Watanabe, Y. Sakamoto, T. Suzuki and S. Yamago, J. Am. Chem. Soc., 2011, 133, 8354-8361.

29 M. Ball, Y. Zhong, B. Fowler, B. Zhang, P. Li, G. Etkin, D. W. Paley, J. Decatur, A. K. Dalsania, H. Li, S. Xiao, F. Ng, M. L. Steigerwald and C. Nuckolls, J. Am. Chem. Soc., 2016, 138, 12861-12867.

30 M. Iyoda, J. Yamakawa and M. J. Rahman, Angew. Chem., Int. Ed., 2011, 50, 10522-10553.

31 T. Iwamoto, Y. Watanabe, H. Takaya, T. Haino, N. Yasuda and S. Yamago, Chem.-Eur. J., 2013, 19, 14061-14068.

32 Y. Nakanishi, H. Omachi, S. Matsuura, Y. Miyata, R. Kitaura, Y. Segawa, K. Itami and H. Shinohara, Angew. Chem., Int. Ed., 2014, 53, 3102-3106.

33 B. Zhang, R. Hernández Sánchez, Y. Zhong, M. Ball, M. W. Terban, D. Paley, S. J. L. Billinge, F. Ng, M. L. Steigerwald and C. Nuckolls, Nat. Commun., 2018, 9, 1957.

34 Q. Huang, G. Zhuang, H. Jia, M. Qian, S. Cui, S. Yang and P. Du, Angew. Chem., Int. Ed., 2019, 58(19), 6244-6249.

35 T. Nakamura, S. Tsukuda and T. Nabeshima, J. Am. Chem. Soc., 2019, 141, 6462-6467.

36 E. R. Darzi, E. S. Hirst, C. D. Weber, L. N. Zakharov, M. C. Lonergan and R. Jasti, ACS Cent. Sci., 2015, 1, 335-342.

37 B. Zhang, M. Tuan Trinh, B. Fowler, M. Ball, Q. Xu, F. Ng, M. L. Steigerwald, X.-Y. Zhu, C. Nuckolls and Y. Zhong, J. Am. Chem. Soc., 2016, 138, 16426-16431.

38 J. M. Van Raden, E. R. Darzi, L. N. Zakharov and R. Jasti, Org. Biomol. Chem., 2016, 14, 5721.
39 E. Kayahara, L. Sun, H. Onishi, K. Suzuki, T. Fukushima, A. Sawada, H. Kaji and S. Yamago, J. Am. Chem. Soc., 2017, 139, 18480-18483.

40 S. Nishigaki, M. Fukui, H. Sugiyama, H. Uekusa, S. Kawauchi, Y. Shibata and K. Tanaka, Chem.-Eur. J., 2017, 23, 7227-7231.

41 M. L. Ball, B. Zhang, Q. Xu, D. W. Paley, V. C. Ritter, F. Ng, M. L. Steigerwald and C. Nuckolls, J. Am. Chem. Soc., 2018, 140, 10135-10139.

42 M. Ball, B. Fowler, P. Li, L. A. Joyce, F. Li, T. Liu, D. Paley, Y. Zhong, H. Li, S. Xiao, F. Ng, M. L. Steigerwald and C. Nuckolls, J. Am. Chem. Soc., 2015, 137, 9982-9987.

43 J. Zaumseil and H. Sirringhaus, Chem. Rev., 2007, 107, 12961323.

44 C. D. Dimitrakopoulos and P. R. L. Malenfant, Adv. Mater., 2002, 14, 99-117.

45 J. E. Anthony, A. Facchetti, M. Heeney, S. R. Marder and X. W. Zhan, Adv. Mater., 2010, 22, 3876-3892.

46 Z. Chen, U. Baumeister, C. Tschierske and F. Würthner, Chem.-Eur. J., 2007, 13, 450-465.

47 T. E. Kaiser, V. Stepanenko and F. Würthner, J. Am. Chem. Soc., 2009, 131, 6719-6732.

48 F. Würthner, C. R. Saha-Möller, B. Fimmel, S. Ogi, P. Leowanawat and D. Schmidt, Chem. Rev., 2016, 116, 962-1052.

49 P. George, M. Trachtman, C. W. Bock and A. M. Brett, Theor. Chim. Acta, 1975, 38, 121-129.

50 S. M. Bachrach and D. Stück, J. Org. Chem., 2010, 75, 65956604.

51 Y. Segawa, H. Omachi and K. Itami, Org. Lett., 2010, 12, 2262-2265.

52 J. B. You, L. T. Dou, K. Yoshimura, T. Kato, K. Ohya, T. Moriarty, K. Emery, C. C. Chen, J. Gao, G. Li and Y. Yang, Nat. Commun., 2013, 4, 10.

53 M. J. Ahrens, M. J. Tauber and M. R. Wasielewski, J. Org. Chem., 2006, 71, 2107-2114.

54 G. Goretzki, E. S. Davies, S. P. Argent, J. E. Warren, A. J. Blake and N. R. Champness, Inorg. Chem., 2009, 48, 10264-10274.

55 R. K. Dubey, A. Efimov and H. Lemmetyinen, Chem. Mater., 2011, 23, 778-788.

56 R. K. Dubey, M. Niemi, K. Kaunisto, A. Efimov, N. V. Tkachenko and H. Lemmetyinen, Chem.-Eur. J., 2013, 19, 6791-6806.

57 B. Xu and N. J. Tao, Science, 2003, 301, 1221-1223.

58 L. Venkataraman, J. E. Klare, C. Nuckolls, M. S. Hybertsen and M. L. Steigerwald, Nature, 2006, 442, 904.

59 M. S. Hybertsen, L. Venkataraman, J. E. Klare, A. C. Whalley, M. L. Steigerwald and C. Nuckolls, J. Phys.: Condens. Matter, 2008, 20, 374115.

60 T. A. Su, M. Neupane, M. L. Steigerwald, L. Venkataraman and C. Nuckolls, Nat. Rev. Mater., 2016, 1, 16002. 